\title{
Navigating Academia: A Mixed Methods Analysis of Sense of Community, Student-Faculty Relationships, and Student Success
}

Camilla Cummings

Portland State University

Follow this and additional works at: https://pdxscholar.library.pdx.edu/mcnair

Part of the Community Psychology Commons, Education Commons, and the Social Psychology Commons

Let us know how access to this document benefits you.

\section{Recommended Citation}

Cummings, Camilla (2016) "Navigating Academia: A Mixed Methods Analysis of Sense of Community, Student-Faculty Relationships, and Student Success," PSU McNair Scholars Online Journal: Vol. 10: Iss. 1, Article 4.

https://doi.org/10.15760/mcnair.2016.3

This open access Article is distributed under the terms of the Creative Commons Attribution-NonCommercialShareAlike 4.0 International License (CC BY-NC-SA 4.0). All documents in PDXScholar should meet accessibility standards. If we can make this document more accessible to you, contact our team. 
Portland State University McNair Research Journal 2016

Navigating Academia: A Mixed Methods Analysis of Sense of Community, Student-Faculty Relationships and Student Success

By

\section{Camilla Cummings}

Faculty Mentor: Greg Townley, PhD

Citation: Cummings, C., Townley, G., Navigating Academia: A Mixed Methods Analysis of Sense of Community, Student-Faculty Relationships and Student Success. Portland State University McNair Scholars Online Journal, Vol. 10, Year: 2016 


\section{Abstract}

College enrollment in the United States is higher than it has ever been before. However, there is a strong delineation between students who know how to use education as a tool and students who do not. This study aims to understand the importance of sense of community and faculty-student relationships to student success and engagement. This cross-sectional study used quantitative and qualitative methodologies to examine sense of community and engagement in 210 undergraduate students. Sense of community, mentorship, university experiences, social intelligence, and demographic variables were analyzed using bivariate correlations, multiple linear regression, t-tests, and thematic content analysis. The research literature in this area supports the notion that higher social intelligence, sense of community and quality of mentoring relationships are all beneficial for long term success in academia and elsewhere; however, there is no published research to date that critically explores the relationship between these three phenomena. Results suggest that sense of community, mentorship, university experiences and social intelligence are important for academic success. Further, results highlight a difference in sense of community between transfer students and non-transfer students. This study suggests the need to examine these primary study variables in greater depth. These findings have ramifications throughout the fields of education and psychology because if we know what comprises the ability to use education as a tool, we can help others use this tool wisely to meet both professional and personal goals.

Keywords: Community Psychology, Social Psychology, Education 


\section{INTRODUCTION}

Student enrollment in higher education is at an all-time high. Between 2002 and 2012, undergraduate enrollment rose 24 percent (U.S. Department of Education, 2015). Although more students are enrolling in college than ever before, they are still questioning whether or not it is a good investment (Psacharopoulos \& Patrinos, 2004); and further, are feeling unsure as to how they can get the most out of their education. Explanations of student success are diverse and nuanced, but many researchers use the overarching meta-construct of student engagement (Fredricks, Blumenfeld, and Paris, 2004).

Student engagement is increasingly researched, theorized, and debated with a growing interest in measuring student outcomes (Zepke \& Leach, 2010). Measuring student engagement is often suggested as a proxy for assessing the quality of education (Kuh, 2009), which is indicative of its critical role in educational outcomes. As theorized by Kahu (2013), student engagement has structural influences (e.g., university factors such as policies and culture; and student factors such as background and support), and psychosocial influences (e.g., university staff support, workload, relationships, student motivation, self-efficacy, and identity). Kahu (2013) also purported that student engagement has proximal consequences, (i.e., achievement, learning, satisfaction, and well-being) and distal consequences (i.e., retention, work success, lifelong learning, citizenship, and personal growth). Using this conceptual framework, this study aims to better understand the student experience and to explore the structural and psychosocial influences of student engagement. The following sections will present the theoretical and empirical underpinnings of the primary study variables; articulate specific study aims and methods; and discuss the implications of findings for research and practice.

\section{Sense of Community}

Sense of Community (SOC) represents an overarching personal quality of strong attachment within a group. The psychological sense of community as a theoretical construct refers to "the importance of belonging to and being an integral part of a larger collectivity" (Townley et al., 2013, p. 279, Sarason, 1974). McMillan and Chavis (1986) define SOC as "a feeling that members have of belonging, a feeling that members matter to one another and to the group, and a shared faith that members' needs will be met through their commitment to be together" (p. 9).

The following four components are fundamental to McMillan and Chavis' conceptualization of sense of community as an empirical framework: (a) membership, feelings of emotional safety with a sense of belonging and identification; (b) influence, exertion of one's self on the community with reciprocal impact of the community on oneself; (c) integration and fulfillment of needs, physical and psychological needs met, thereby reinforcing one to behave in a manner acceptable to the community; and (d) shared emotional connection, positive affect related to community membership (Pretty, Bishop, Fisher, \& Sonn, 2006). The literature has shown that sense of community is related to active participation in community life (Chavis \& Wandersman, 1990), subjective well-being (Prezza \& Constantini, 1998), higher grade point average (Townley et al., 2013), and perceptions of belonging and connectedness (Sonn \& Fisher, 1996). Most pertinent to students' SOC in higher education, McMillan \& Chavis (1986) purported that membership to a group or community includes a "sense of belonging and identification... that one fits in the group and has a place there" (p. 10) as well as a "personal investment [which] will provide a feeling that one has earned a place in the group and that, as a consequence of this personal investment, membership will be more meaningful and valuable" (p. 10).

Sarason (1974) passionately claimed that the qualities inherent to sense of community are so important to human functioning that their absence may lead to isolation, loneliness, and depression, while further research supports that respondents with greater SOC report more 
happiness, self-efficacy and coping strategies (Davidson \& Cotter, 1991). With this in mind, it is critical to explore SOC in student populations. Many students, especially from diverse backgrounds report feeling "imposter syndrome" or rather, a feeling of fraudulence or that they do not belong in an educational or upper class setting due to their ethnic, racial or lower class background. Mack (2006) described this phenomenon as follows:

Although a college degree does increase the income of individuals, the educational experience should not be misrepresented as a free ride to upward mobility. Hidden beneath the seductive belief that education is the great equalizer is the assumption that being from the working class is a deficit or a liability... Marginalized students struggle to pass for the right kind of students, living in fear of being unmasked as undeserving (p. 54).

Perhaps it is this reason that women and racial minorities report a greater discrepancy between their actual and ideal sense of community (Townley et al., 2013). In order to create an equitable educational environment where students can use their education as a tool for upward mobility or to otherwise improve their lives, it is crucial to better understand how students cultivate a strong sense of community and form an academic identity.

\section{University Environment and Mentoring}

Similar to SOC, University Environment is a concept that represents the degree to which students feel welcome in the university environment and the impact of institutional factors (e.g., class size, perceptions of faculty, etc.) on their experiences. Research shows that higher scores on the University Environment scale are related to greater comfort within the institution, a willingness to seek out help (Gloria, Hird, \& Navarro, 2001), and academic persistence (i.e., whether or not students continue on from term to term and follow through to graduation) (Castillo et a., 2006).

Further, mentorship plays a significant role in the academic experience of students because of the discipline-specific apprenticeship model that higher education follows. Nora and Crisp (2007) proposed a theoretical framework comprising the latent functions of mentoring; these include: (a) psychological and emotional support, cultivating a supportive relationship with encouragement, help identifying problems, and both moral and emotional support; (b) degree and career support, assessment of goals and help with decision-making; (c) academic subject knowledge support, acquisition of specific knowledge and skills while also learning conventions and norms of a specific field; (d) and the existence of a role model, having someone to model appropriate behavior, and to learn from current or past successes and failures. In addition to the latent benefits, there are also manifest or tangible benefits, such as letters of recommendations or access to education/careerrelated information that they were not likely to have received otherwise (Freeman, 1999). Moreover, there are social-psychological theoretical underpinnings of mentorship that are worthy of note. Just the mere fact of having a mentor aids in identity development and formation, especially that of a professional or academic identity. Leading impression management researcher Barry Schlenker (1994) articulated it best when he said "it's because when people act in certain ways, and someone is watching, they become obligated to show some consistency in their personalities" (p. 21). Finally, mentorship has been linked to greater self-efficacy among students and increased confidence in their ability to make decisions, problem-solve, and achieve goals (Cosgrove, 1986).

\section{Social Intelligence}

Finally, social intelligence refers to the ability to adapt to, shape, and select everyday environments (Sternberg, 2000). Bourdieu (2005) adds that habitus, another term for social intelligence, is an internalized understanding of reality, as well as habits of dispositions to act, think, and feel in 
certain ways learned from one's social or cultural environment. Sternberg refers to social intelligence as "practical intelligence" and claims that social intelligence is situational and contextual, which is why this study employs the use of social intelligence in a higher education setting. Researchers have found that the most crucial components of any social intelligence are: (a) an extensive knowledge of rules and norms in human relations; (b) having developed effective interpersonal skills; (c) understanding and taking on the perspective of other people; (d) adapting well in social situations and being open to new experiences, ideas, and values; (e) and, being warm and caring (Kelly, 2010; Kosmitzki \& John, 1993).

According to a study conducted by Thomas (2002), student success was mediated by their ability to adapt to the social climate of the institution; and, therefore, certain groups of students were more likely to perform better if they came from a majority, or dominant, social group. Specifically, if students feel that they do not fit in, or that their social and cultural practices are inappropriate or undervalued, they may experience negative academic and personal outcomes compared to students from dominant social groups (Bourdieu \& Wacquant, 1992; Thomas, 2002). It is for this reason that understanding student engagement and sense of community inherently includes whether or not a student knows how to navigate the social environment of the university. Having little knowledge of or background with a set of rules, norms and values would put a student in a more precarious position when navigating the university system, and this study aims to understand if this impacts sense of community, student-faculty relationships, and grade point average.

\section{Study Aims}

As indicated by the review above, the overarching goal of this study is to better understand the influence of SOC, student-faculty relationships, and social intelligence on the academic experiences of undergraduate students. The specific aims of the study are as follows: (a) to investigate potential differences of SOC across student variation and demographic groups; (b) to examine how university experiences, mentorship and social intelligence affect SOC; (c) to assess the relationship between primary study variables and grade point average; and, (d) to explore the importance that SOC plays in a student's academic experience.

\section{METHODS}

\section{Participants}

The sample for the quantitative component of this study consists of 210 undergraduate students enrolled in courses at Portland State University. Of the 210 participants, $144(72 \%)$ were female, $49(24.5 \%)$ were male, and 7 (3.3\%) identified as either transgender or gender non-binary. The racial composition of the sample was as follows: $130(65 \%)$ were White, $4(2 \%)$ were Black, 17 (8.5\%) were Latino, 19 (9.5\%) were Asian American, one (.5\%) was Native American, one $(.5 \%)$ was Hawaiian/other Pacific Islander, five (2.5\%) reported "Other" race/ethnicity, and 23 (11.5\%) reported being multiracial. Of the 210 participants, $116(57.1 \%)$ were transfer students and 85 $(42.5 \%)$ were first generation students. Additionally, $174(87 \%)$ of respondents live off campus and $22(11 \%)$ respondents reported living in University residential housing.

The qualitative portion of the study consists of 16 undergraduate students at Portland State whose demographics were comparable to the general study sample.

\section{Procedures}

Students were recruited from classes taught at Portland State University. Informational emails were sent out to professors through departmental listservs and personal email in the University 
Studies department, the Honors department and the Philosophy department. Emails were also sent to Capstone faculty, Psychology faculty, and Sociology faculty. Professors were given the option of offering extra credit for student participation in the online survey. Completion of the survey was both anonymous and voluntary. As per Institutional Review Board approval, there was approximately a three-month window for data collection. Completion of surveys was tracked throughout data collection using an online survey platform. A gift card was offered to one student at random to incentivize students' participation.

Students who participated in the online survey could indicate that they would like to be contacted to participate in the focus group portion of the study. Randomly selected students were then contacted and offered three time slots to participate in the focus group. Focus group participation was voluntary but not anonymous or confidential because of the nature of focus groups. Gift cards were offered to incentivize students' participation.

\section{Measures}

SOC. Sense of Community was measured via the 24-item Sense of Community Index 2 (SCI-2; Chavis, Lee, \& Acosta, 2008). Participants responded to 24 items assessing perceptions of community membership, influence, fulfillment of needs, and shared emotional connection. SCI-2 items were rated on a 4-point scale, ranging from 1 (not at all) to 5 (completely). Minor modifications were made to several SCI items to reflect the context of this study sample (i.e., changing the word "community" to "university"). The SCI-2 has demonstrated strong reliability and validity (Chavis et al., 2008). The Cronbach alpha for the scale in this sample was .95. Sum scores (created by adding the 24 scale items) ranged from 24 to $96(M=53.8, S D=14.4)$.

Student-Faculty Relationships. Student-Faculty Relationships were measured using the 25-item College Mentoring Scale (CMS; Lin, M. M, 2011). These items include four interrelated latent variables: psychological and emotional support, degree and career support, academic subject knowledge support, and the existence of a role model. CMS items were rated on a 5-point scale ranging from 1 (strongly disagree) to 5 (strongly agree). Several studies show empirical support for the CMS (e.g., Gloria, 1993; Lin, M.M., 2011; Nora \& Crisp, 2007). The Cronbach alpha for the scale in this sample was .97. Sum scores (created by adding the 25 scale items) ranged from 25 to 120. $(M=80.8, S D=21.6)$.

University Environment. University Environment, or rather the extent to which students feel welcome in the university environment, was measured using the 14-item University Environment Scale (UES; Gloria \& Robinson Kurpius, 1994). UES items were rated on a 4-point scale ranging from 1 (strongly disagree) to 4 (strongly agree). A number of studies have demonstrated the UES' construct validity and, more notably, its validity and applicability to students from diverse racial and SES groups (e.g., Castillo et al., 2006; Gloria et al., 1999, 2001, 2003). The Cronbach alpha for the scale in this sample was .80. Sum scores (created by adding the 14 scale items) ranged from 14 to 56. $(M=37.8, S D=3.6)$.

Social Intelligence. Social Intelligence, or rather a student's practical intelligence in the university environment, was measured using the 33-item Test of Social Intelligence in the College Classroom (Kelly, A.E., 2010). Test of Social Intelligence items are questions regarding features or scenarios in a college setting. Sample questions include "How much training does a professor typically get on how to teach?" and "What does a typical professor at a major university do in the summer?". Respondents choose an answer from a series of multiple choice options where there is a correct answer. For this reason, a Cronbach alpha score or other score of internal consistency is inappropriate (Bland \& Altman, 1997). Although there is little psychometric information published for this new measure, it was developed specifically for the university environment and modeled after what research shows to be the essential features social intelligence as a construct (Kosmitzki 
\& John, 1993). Sum scores (created by adding the correct responses from the 33 scale items) ranged from 4 to $25(M=15.3, S D=3.7)$.

Academic Outcomes. This study used self-reported grade point average (GPA) as an additional outcome variable evaluating student success and engagement. GPA's ranged from 1.65 to 4.0 (M= $3.39, S D=.45$ )

\section{Data Analysis}

Individuals who were missing the majority of data on two or more scales included in the regression model were deleted from the dataset. For cases in which individuals were missing less than $10 \%$ of items within a scale, person mean imputation - which calculates the mean across each person's available item responses and imputes this mean for each missing value for that particular person was used. This approach has been recommended in the literature (e.g., Bernaards \& Sijtsma, 2000).

The influence of University Environment, Mentoring, Social Intelligence and demographic variables on Sense of Community was assessed using a multiple linear regression using two blocks. The first block included age, gender, race, and transfer status; and the second block included the scale score for University Environment, Mentoring and Social Intelligence. A correlation matrix was employed to examine the relationship between Sense of Community, Social Intelligence, Mentoring, University Environment and GPA. Independent samples $t$-tests examined potential differences in Sense of Community of racial groups, gender, transfer status and whether or not the student lived on campus.

For the qualitative component of this study, focus group interviews were transcribed verbatim and analyzed using thematic content analysis. Specifically, transcripts were analyzed for student perceptions of and experiences with the primary study variables (e.g., Sense of Community and Mentoring). Illustrative quotes are presented to highlight central thematic categories discussed by participants.

\section{RESULTS}

A multiple linear regression analysis was conducted, regressing Sense of Community on demographic variables, Mentoring, University Environment and Social Intelligence.

Table 1 below provides the results of this analysis. Together, Mentoring, University Environment and Social Intelligence accounted for a significant proportion of variance in respondents SOC, $R^{2}$ $=.34, F(3,210)=12.17, p<.01$. Controlling for demographic variables, Mentoring was positively related to SOC, $B=.33, t(210)=8.3, p<.01$. Furthermore, University Environment was positively related to SOC, $B=1.06, t(210)=3.7, p<.01$. In contrast, Social Intelligence was not significantly related to SOC when controlling for demographic variables, $B=.09, t(210)=.38, p=$. 72. The only demographic variable that significantly predicted SOC was transfer status, $B=4.23$, $t(210)=2.2, p<.05$, which is discussed in more detail below.]

\section{Table 1}

Results of a Multiple Linear Regression of Demographic Variables, Mentoring, University Experiences and Social Intelligence on Sense of Community

\begin{tabular}{lccc}
\hline & $B$ & $S E(B)$ & $t$ \\
\hline Intercept & -17.02 & 12.09 & -1.41 \\
Race & -.66 & 1.81 & -.37
\end{tabular}




\begin{tabular}{lccc} 
Gender & -3.40 & 1.94 & -1.76 \\
Age & .09 & .14 & .64 \\
Transfer Status & 4.23 & 1.95 & $2.16^{*}$ \\
Mentoring & .33 & .04 & $8.28^{* *}$ \\
University Environment & 1.06 & .29 & $3.67^{* *}$ \\
Social Intelligence & .09 & .23 & .38 \\
\hline
\end{tabular}

Notes: $* p<.05, * * p<.01 . N=210$. Model $R^{2}=.34, F(3,210)=12.17, p<.01$.

A correlational analysis was conducted to estimate the association between University Experiences, Social Intelligence, Sense of Community, Mentoring and GPA (See Table 2). The correlation between SOC and Mentoring is positive and significant $(r=.53, p<.01)$. There was also a moderate, positive correlation between SOC and University Environment $(r=.21, p<.01)$. Social Intelligence was moderately, positively correlated with Mentoring $(r=.18, p<.05)$ and positively correlated with $\operatorname{GPA}(r=.21, p<.01)$. Mentoring was also positively correlated with GPA $(r=.21, p<.01)$

Table 2

Results of a Correlation Matrix of University Experiences, Mentoring, Social Intelligence and Sense of Community on Grade Point Average.

\begin{tabular}{lccccccc}
\hline & $M$ & $S D$ & 1. & 2. & 3. & 4. & 5. \\
\hline 1. SOC & 53.8 & 14.4 & 1 & .11 & $.53^{*}$ & $.21^{* *}$ & .08 \\
& & & & & $*$ & & \\
2. Social Intelligence & 15.3 & 3.7 & .11 & 1 & $.18^{*}$ & -.03 & $.21^{* *}$ \\
$\begin{array}{l}\text { 3. Mentoring } \\
\begin{array}{l}\text { 4. University } \\
\text { Environment }\end{array}\end{array}$ & 80.8 & 21.6 & $.53 * *$ & $.18^{*}$ & 1 & .02 & $.21^{* *}$ \\
5. GPA & 37.8 & 3.6 & $.21^{* *}$ & -.03 & .02 & 1 & -.001 \\
& 3.39 & .45 & .08 & $.21 * *$ & $.21 *$ & -.001 & 1 \\
\hline
\end{tabular}

Notes: $\mathrm{N}=210 . * \mathrm{p}<.05, * * \mathrm{p}<.01$.

An independent-samples $t$-test was conducted to evaluate whether or not transfer students and non-transfer students' SOC scores differed. Mean SOC index scores for transfer students $(M=51.6$, $S D=12.03$ ) were significantly lower than the mean SOC index scores for non-transfer students $(M=56.14, S D=15.89), t(210)=-2.29, p<.005, d=-.32$. Figure 1 shows a graphical display of the results. The results indicate that non-transfer students reported a higher Sense of Community than transfer students. There were no statistically significant mean differences between other demographic groups (i.e., age, gender, race, on campus housed vs. off campus housed). 


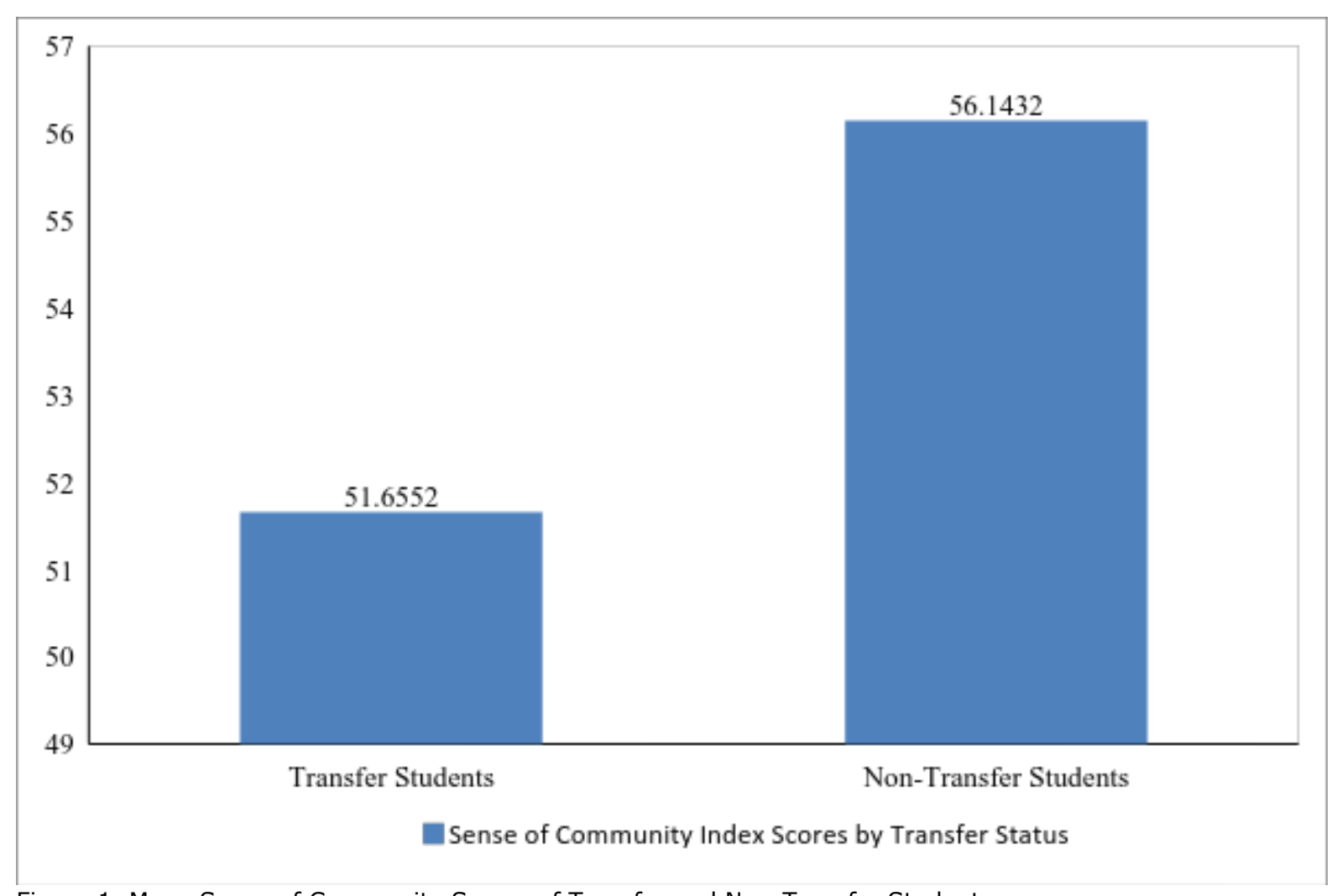

Figure 1. Mean Sense of Community Scores of Transfer and Non-Transfer Students

\section{Qualitative Results}

Findings from the qualitative component of this study help to contextualize the quantitative results presented above. For example, when asked to reflect on the role that Sense of Community plays in their lives, one respondent said the following:

I think it depends on the community. Um, but at least from my side, it usually is a bettering thing. I like being around people that can teach me things. I can learn from [them] as well as share a common interest and common passions, so usually part of the community is being able to um, learn from each other. Not necessarily even academically, just in general... in life. Being able to kind of sculpt my identity based on the types of things that I learn, no matter what they are.

Many focus group respondents agreed that a large function of community and belonging to them was emotional support and an increased well-being. One respondent claimed that, "It's definitely emotional support. Because I mean, a few people have mentioned just how lonely it can be." Another participant echoed this sentiment:

[It's important for me to] especially on an emotional level, like reach out and communicate.

[If I don't have that support] I have a tendency, it like, really affects my well-being. So in order to do that, you need to have people and in that way, it's highly important for me to have a community of some sort.

Most students maintained that they did not identify with the overall school community but had their needs of membership, influence, integration and fulfillment of needs, and shared emotional connection met through niche communities. The vast majority of focus group participants expressed the importance of niche communities and especially for discipline specific communities as essential to their SOC and academic engagement. One participant said, 
I think subject-specific communities are really important. I mean, for me, I have my group of friends who are from all over. My friends are Computer Science and Women's Studies and, you know, the whole laundry list. But, more than half of them could give a crap about my interests, and trying to have some of those conversations can be really difficult and isolating... um, so it is nice to have those kinds of friends that kind of share that same passion and have a similar knowledge base.

Participants expressed that their personal investment to the discipline or subject aided in their sense of belonging and feeling that they had earned their place in the group. However, when asked about the effects of a lack of sense of community, respondents supported notions of loneliness, isolation and a decreased sense of well-being. One respondent said the following:

In general, I feel completely anonymous here... It's really difficult because I come from a really small town... so, being anonymous was really bizarre to me at first. There's a lot of freedom involved, like people don't have expectations of me, really. Like my classrooms are really large, my teachers don't know who I am...You know, I was a scantron... So um, yeah, I hold myself to my own performance standards. But, it's kind of weird. It's weird like sitting and eating lunch and not knowing anyone.

Additionally, focus group participants spoke to the redeeming qualities of having a mentor when their SOC or sense of belonging was low. One student said, "Not having a community disconnects me from it a little bit, so having someone kind of 'in my corner' in some sense is really vital to me." Participants also remarked about the importance of getting along interpersonally with a mentor in order to cultivate a strong professional relationship. Common attributes that most participants noted as important for a successful student-faculty relationship were having similar communication styles; perceiving the mentor to have unconditional positive regard. For instance, one student reported,

"I think the best part about that relationship is just how encouraging she is. I never come to her with an idea and she's like 'Oh, I don't know if you should do that" 'or 'Maybe you should do it like this...' It's always like, 'Yeah! Do whatever! Make it happen!"

Other common attributes reported in the focus groups were the common interests and cultivation of their autonomy as scholars. For example, one respondent said the following:

For me it was like similar drives and work ethics. I choose mentors that push me; they don't just give me the answer. They kind of hint at what they want; but then if I do all of the legwork for them, they show me the appreciation and the reward. I've had to go out of my way for my faculty, and it makes me work harder.

Students also articulated the importance of their mentor being responsive and warm, and essential for role performance and modeling behavior, for example, "They help to model behavior in showing me that 'Oh, I can totally be myself and still kind of find my niche and still kind of, I don't know, find my adulthood and professionalism.'"

Furthermore, many students reported the importance of having a reciprocal relationship where both parties are putting in time and energy and obtaining tangible benefits. Some of the latent benefits supported by the focus group findings were emotional support, practical support/advice, the teaching of skills or discipline specific social capital, as well as impression management. The manifest functions supported by focus group findings were letters of recommendation, information about important opportunities, networking connections, etc.

Respondents cited institutional factors (e.g., large classes, adjunct faculty being spread too thin, advisors having overly large workloads) as primary reasons for not seeking out or cultivating student-faculty relationships. One student said that their professor "...didn't care about the development of the student. He cared about- he just kind of showed up to class because he had to... [that was] the worst experience and [I felt] like I was paying this person to not-to care less." 
Another respondent said "I wonder how much of that is just, they don't have enough time to even devote, like the bandwidth to deal with that many people."

Students also cited individual reasons, such as a general unawareness that it was important to have a mentor and perceiving their professors as being cold, distant, and unavailable. The most salient reason expressed for not connecting with faculty was that the instructors were noninclusive, prejudiced, unprofessional, or disorganized. For example, one student said He would make racist and sexist remarks. And I lost all respect for the guy immediately.... Like, no we can't totally, overnight, bridge the gap and like pay magical reparations and suddenly have a mixed race, mixed gender demographic represented in the faculty because change doesn't happen overnight like that- and it wouldn't be sustainable if we forced it, you know.....But yeah, to see [institutionalized and systemic oppression] reinforced by people in mentorship positions is pretty infuriating.

\section{DISCUSSION}

The current study has important implications for future research and practice in community psychology, social psychology, and higher education. To our knowledge, this is the first study of its kind to employ mixed methods to investigate the relationship between SOC, student-faculty relationships, university environment and social intelligence. Analyses revealed that mentoring (student-faculty relationships), university environment, and transfer status were most predictive of sense of community. It makes conceptual sense that if a student feels comfortable in their environment, they are more likely to feel a sense of belonging because these two phenomena intuitively go together. Similarly, the notion that mentorship aids in the development of SOC is theoretically consistent. If a mentor is accepting and provides support, this would increase a student's sense of belonging as well as the development of specialized skills, knowledge, social intelligence and role performance that would also make a student more likely to fit in and belong.

Further, results suggest that mentoring and university environment are most closely correlated with SOC; social intelligence is most correlated with student-faculty relationships and GPA; and mentoring is also correlated with GPA. These results highlight how critical mentorship is for a student's sense of community, social intelligence and GPA. The relationship between social intelligence and GPA is one that has a lot of face validity. If students are better at learning the rules and norms of the cultural practices required of university students, they are more likely to engage with course material, classmates, and professors in a way that their instructor intended; which would elicit higher grades and evaluations of performance and mastery. These findings support the use of an apprenticeship model of academia and are consistent with social intelligence theories outlined in the literature.

We found that transfer students reported higher sense of community than non-transfer students, which is consistent with previous research reporting a decrease in SOC among transfer students (Townley et al., 2013). Contrary to past research, however, our results did not indicate any statistically significant differences in mean SOC scores across demographic groups (i.e., age, gender, race, on campus housed vs. off campus housed). This may be due in part to the homogenous nature of our sample (i.e., participants were primarily White, female, younger), as will be discussed in more detail below.

\section{Limitations and Suggestions for Future Research}

Several study limitations are worth noting. First, the small sample size and homogeneity of the sample must be recognized. Although the sample size was large enough to detect significant 
relationships between primary study variables and SOC, there may have been insufficient power to detect other potential associations. Further, the sample lacked diversity in race/ethnicity, gender, sexual orientation, and geographic location. Thus, we are missing the experiences of students who may be engaging with their community and academia differently than the students included in the current study. A future study should collect data from a larger number of participants who are more representative of the demographic composition of the population. Further, a study including different geographic locations as well as different types of institutions would increase the generalizability of study findings and enrich the literature on the cultural differences and institutional factors impacting sense of community, engagement, and student success. Making these changes would increase both the variability of results and diversity of experience, while also increasing the likelihood of detecting relationships that plausibly exist in the real world.

Second, causation cannot be inferred from the results of this study's cross-sectional design. The main limitation with this design is that there is no indication of chronological order of the primary study variables. It is not clear how and when students increase their social intelligence, cultivate mentoring relationships, form perceptions of their university environments, and develop a sense of community. Further, it is not clear from the current study how these phenomena affect one another over time. To address these issues, a future study should record students' experiences over a course of time. A longitudinal study design would facilitate better understanding of how these variables interact over time and across different settings and demographics.

Moreover, this study used self-report measures. Particularly, mentorship and GPA are susceptible to self-report biases such as the social desirability effect. It would be helpful in future research to obtain GPA from institutional records as well as additional data collected directly from mentors to triangulate student reports. Additionally, the current study took a community psychological (i.e., contexualist) approach rather than an individualistic approach and therefore did not include measures such as individual motivation, academic persistence, and other psychological characteristics that may account for additional variance in outcomes.

Finally, the Social Intelligence scale lacked empirical validation and psychometric information. While this measure did yield significant results, a future study should focus on assessing the psychometric characteristics of this scale.

\section{Conclusions and Practical Implications}

Navigating higher education is often an arduous and tumultuous experience that may be more difficult for certain kinds of students. Results of the current study highlight the importance of a contextualized, holistic understanding of students' sense of community and mentoring relationships. We found that student-faculty relationships were most strongly related to and predictive of higher sense of community, GPA, and social intelligence. These findings emphasize the importance of creating opportunities for students to cultivate mentoring relationships. Additionally, we found that transfer students had a lower sense of community than non-transfer students, which brings attention to the need to better integrate students into their post-transfer institutions. Indeed, strong supportive mentoring relationships may be most critical for transfer students. Similarly, qualitative results suggest the importance of developing sub-communities (e.g., discipline-specific student groups) within the larger campus community, as these may help to combat feelings of isolation and loneliness experienced by many students. When assessing outcomes in higher education, it is important to prioritize students' emotional and social engagement as well as institutional and environmental factors as key indicators of their academic success. 


\section{REFERENCES}

Attride-Stirling, J. (2001). Thematic networks: an analytic tool for qualitative research. Qualitative research, 1(3), 385-405.

Bernaards, C. A., \& Sijtsma, K. (2000). Influence of imputation and EM methods on factor analysis when item nonresponse in questionnaire data is nonignorable. Multivariate Behavioral Research, 35(3), 321-364.

Bland, J. M., \& Altman, D. G. (1997). Statistics notes: Cronbach's alpha. Bmj,314(7080), 572.

Bourdieu, P. (2005). Habitus. Habitus: A sense of place, 2, 43-49.

Bourdieu, P., \& Wacquant, L. J. (1992). An invitation to reflexive sociology. University of Chicago press.

Bryman, A. (2006). Integrating quantitative and qualitative research: how is it done?. Qualitative research, 6(1), 97-113.

Castillo, L. G., Conoley, C. W., Choi-Pearson, C., Archuleta, D. J., Phoummarath, M. J., \& Van Landingham, A. (2006). University environment as a mediator of Latino ethnic identity and persistence attitudes. Journal of Counseling Psychology, 53(2), 267.

Chavis, D.M., Lee, K.S., \& Acosta J.D. (2008). The Sense of Community (SCI) Revised: The Reliability and Validity of the SCI-2. Paper presented at the 2nd International Community Psychology Conference, Lisboa, Portugal.

Chavis, D. M., \& Wandersman, A. (1990). Sense of community in the urban environment: A catalyst for participation and community development.American journal of community psychology, 18(1), 55-81.

Cosgrove, T. J. (1986). The effects of participation in a mentoring-transcript program on freshmen. Journal of College Student Personnel.

Davidson, W. B., \& Cotter, P. R. (1991). The relationship between sense of community and subjective well-being: A first look. Journal of Community Psychology, 19(3), 246-253.

Fredricks, J. A., Blumenfeld, P. C., \& Paris, A. H. (2004). School engagement: Potential of the concept, state of the evidence. Review of educational research,74(1), 59-109.

Freeman, K. (1999). No services needed?: The case for mentoring high-achieving African American students. Peabody Journal of Education, 74(2), 15-26.

Gloria, A. M., Hird, J. S., \& Navarro, R. L. (2001). Relationships of cultural congruity and perceptions of the university environment to help-seeking attitudes by sociorace and gender. Journal of College Student Development.

Johnson, R. B., \& Onwuegbuzie, A. J. (2004). Mixed methods research: A research paradigm whose time has come. Educational researcher, 33(7), 14-26.

Kahu, E. R. (2013). Framing student engagement in higher education. Studies in Higher Education, $38(5), 758-773$.

Kelly, A. E. (2010). The Clever Student: A Guide to Getting the Most from Your Professors. Notre Dame, IN: Corby Books.

Kloos, B. (2005). Community science: creating an alternative place to stand?.American journal of community psychology, 35(3-4), 259-267.

Kosmitzki, C., \& John, O. P. (1993). The implicit use of explicit conceptions of social intelligence. Personality and individual differences, 15(1), 11-23.

Kuh, G. D. (2009). What student affairs professionals need to know about student engagement. Journal of College Student Development, 50(6), 683-706.

Mack, N. (2006). Ethical representation of working-class lives: Multiple genres, voices, and identities. Pedagogy, 6(1), 53-78.

McMillan, D. W., \& Chavis, D. M. (1986). Sense of community: A definition and theory. Journal of community psychology, 14(1), 6-23.

Nora, A., \& Crisp, G. (2007). Mentoring students: Conceptualizing and validating the multidimensions of a support system. Journal of College Student Retention: Research, Theory \& Practice, 9(3), 337-356. 
Parker, A. E., Halberstadt, A. G., Dunsmore, J. C., Townley, G., Bryant Jr, A., Thompson, J. A., \& Beale, K. S. (2012). Emotions are a window into one's heart": a qualitative analysis of parental beliefs about children's emotions across three ethnic groups. Monographs of the Society for Research in Child Development, 77(3), 1-136.

Plett, M., Wilson., Bates, R., Allendoerfer, C., Carlson-Jones, D., \& Floyd-Smith, T. (2014). People Matter: The Role of Peers and Faculty in Students' Academic Engagement. Proceedings from American Society for Engineering Education Annual Conference \& Exposition. Indianapolis, IN.

Pretty, G., Bishop, B., Fisher, A., \& Sonn, C. (2007). Psychological sense of community and its relevance to well-being and everyday life in Australia. The Australian Community Psychologist, 19(2), 6-25.

Prezza, M., \& Costantini, S. (1998). Sense of community and life satisfaction: Investigation in three different territorial contexts. Journal of Community \& Applied Social Psychology, 8(3), 181194.

Psacharopoulos, G., \& Patrinos*, H. A. (2004). Returns to investment in education: a further update. Education economics, 12(2), 111-134.

Quaye, S. J., \& Harper, S. R. (Eds.). (2014). Student engagement in higher education: Theoretical perspectives and practical approaches for diverse populations. Routledge.

Rappaport, J., Davidson, W. S., Wilson, M. N., \& Mitchell, A. (1975). Alternatives to Blaming the Victim or the Environment: Our Places to Stand Have Not Moved the Earth. American Psychologist, 30(4), 525.

Sarason, S. B. (1974). The psychological sense of community: Prospects for a community psychology. Jossey-Bass.

Schlenker, B.R., Dlugolecki, D.W., \& Doherty, K. (1994). The impact of self-presentations on self appraisals and behavior: The power of public commitment. Personality and Social Psychology Bulletin, 20(1), 20-33.

Sonn, C. C., \& Fisher, A. T. (1996). Psychological sense of community in a politically constructed group (Doctoral dissertation, John Wiley \& Sons).

Sternberg, R. J. (2000). Practical intelligence in everyday life. Cambridge University Press.

Thomas, L. (2002). Student retention in higher education: the role of institutional habitus. Journal of Education Policy, 17(4), 423-442.

Townley, G., Katz, J., Wandersman, A., Skiles, B., Schillaci, M. J., Timmerman, B. E., \& Mousseau, T. A. (2013). Exploring the role of sense of community in the undergraduate transfer student experience. Journal of Community Psychology, 41(3), 277-290.

Townley, G., \& Kloos, B. (2011). Examining the psychological sense of community for individuals with serious mental illness residing in supported housing environments. Community mental health journal, 47(4), 436-446.

U.S. Department of Education, National Center for Education Statistics. (2015). Digest of Education Statistics, 2013 (NCES 2015-011).

Zepke, N., \& Leach, L. (2010). Beyond hard outcomes: 'soft' outcomes and engagement as student success. Teaching in Higher Education, 15(6), 661-673. 